IZA DP No. 4654

The Measurement of Child Costs:

A Rothbarth-Type Method Consistent with Scale Economies

Olivier Bargain

Olivier Donni

December 2009 


\title{
The Measurement of Child Costs: A Rothbarth-Type Method Consistent with Scale Economies
}

\author{
Olivier Bargain \\ University College Dublin, \\ Geary Institute, CHILD and IZA \\ Olivier Donni \\ University of Cergy-Pontoise, \\ THEMA and IZA

\section{Discussion Paper No. 4654 \\ December 2009} \\ IZA \\ P.O. Box 7240 \\ 53072 Bonn \\ Germany \\ Phone: +49-228-3894-0 \\ Fax: +49-228-3894-180 \\ E-mail: iza@iza.org
}

Any opinions expressed here are those of the author(s) and not those of IZA. Research published in this series may include views on policy, but the institute itself takes no institutional policy positions.

The Institute for the Study of Labor (IZA) in Bonn is a local and virtual international research center and a place of communication between science, politics and business. IZA is an independent nonprofit organization supported by Deutsche Post Foundation. The center is associated with the University of Bonn and offers a stimulating research environment through its international network, workshops and conferences, data service, project support, research visits and doctoral program. IZA engages in (i) original and internationally competitive research in all fields of labor economics, (ii) development of policy concepts, and (iii) dissemination of research results and concepts to the interested public.

IZA Discussion Papers often represent preliminary work and are circulated to encourage discussion. Citation of such a paper should account for its provisional character. A revised version may be available directly from the author. 
IZA Discussion Paper No. 4654

December 2009

\begin{abstract}
The Measurement of Child Costs: A Rothbarth-Type Method Consistent with Scale Economies*

We propose a new methodology to estimate the share of household income accruing to children (i.e., the cost of children). Following the principle of the Rothbarth approach, the identification of the children's share requires the observation of at least one adult-specific good. However, our method differs from this traditional approach in that it allows measuring economies of scale in the household and indifference scales in Lewbel (2003)'s sense. We illustrate the method with an application on the French Household Budget Survey.
\end{abstract}

JEL Classification: D11, D12, C30, D36, I31, J12

Keywords: consumer demand, collective model, Rothbarth method, cost of children, scale economies, equivalence scales, indifference scales

Corresponding author:

Olivier Bargain

University College Dublin

Belfield

Dublin 4

Ireland

E-mail: olivier.bargain@ucd.ie

\footnotetext{
* We thank Martin Browning for useful comments. We also thank participants to seminars at IZA (Bonn), BETA (Strasbourg), CEPS-INSTEAD (Luxembourg), CORE (Louvain-la-Neuve), THEMA (Cergy-Pontoise) and CREST (Paris). Olivier Bargain is grateful to the Combat Poverty Agency, Dublin, for financial support. Olivier Donni acknowledges financial support from ANR-08-FASH-18 TIPI. All errors or omissions remain ours.
} 


\section{Introduction}

Evaluating what parents spend on children is an essential prerequisite for inferring individual living standards from income data. The Rothbarth method - one of the most common methods of measuring the cost of children - consists in imputing the same level of utility to parents that have the same level of consumption of some adult-specific goods, and deriving from this the fraction of household total expenditure devoted to children. ${ }^{1}$ The underlying intuition is that the welfare of parents is a monotonic increasing function of expenditures on adult goods. This method is simple and relatively sound because founded on an individualistic representation of the household (Gronau, 1988). Nonetheless, a serious problem is concerned with economies of scale, due in particular to the possibility of joint consumption in multi-person household. These scale economies may affect the consumption of adults' goods via a wealth effect as well as price effects and may lead to biased estimations of the cost of children. In fact, as pointed out by Deaton and Muellbauer (1986), the estimations obtained with the Rothbarth method are, in general, abnormally small.

In the present paper, we suggest a variation of the Rothbarth method which is consistent with economies of scale and with parental bargaining. Our approach is closely related to the most recent developments of the literature on collective models. ${ }^{2}$ In particular, Browning, Chiappori and Lewbel (2008) and Lewbel and Pendakur (2008) consider a model where each individual is characterized by a specific utility function and suggest the complete identification of (a) the sharing rule of household resources and (b) the

\footnotetext{
${ }^{1}$ See Deaton, Ruiz-Castillo and Thomas (1989), Gronau (1991) and Lazear and Michael (1988) on the Rothbarth approach. See Browning (1992) and Lewbel (1997) for a survey of the various techniques used to measure the cost of children.

${ }^{2}$ In the traditional literature on collective models, children and their implications for the intrahousehold allocation are generally ignored: empirical estimations are carried out using a sample of childless couples (Chiappori and Browning, 1998; Donni, 2009). We are aware of only two studies on collective models that explicitly deal with children: Bourguignon (1999) and Blundell, Chiappori and Meghir (2005). See Chiappori and Donni (2010) for a survey.
} 
economies of scale, exploiting simultaneously data on couples and single-person households. Browning, Chiappori and Lewbel (2008) account for economies of scale using a (price) transformation à la Barten while Lewbel and Pendakur (2008) adopt an independence of base technology of production, i.e., they suppose that there exists a single function, which is independent of total expenditure, that scales the expenditure of each individual in the household and represents the economies from joint consumption. While these authors focus on childless couples, we extend the approach to families with children and show how to retrieve the sharing rule between wife, husband and children as well as the consumption technology. To represent economies of scale, we follow Lewbel and Pendakur (2008) and make the independence of base assumption. This assumption allows us to achieve identification without price variation, which makes the estimation much more tractable and is also very convenient when using data in which spatial or time variation in prices is limited. In line with the traditional Rothbarth method, we suppose that there is at least one adult-specific good which provides the necessary information to achieve identification of the most important structural components of the model.

Our theoretical results are implemented using the 2000 French Household Budget Survey (INSEE). We suppose that the household expenditures on certain pieces of clothing can be seen as an adult good and we estimate a system of ten budget share equations in order to measure the cost of children and the economies of scale. Our evaluation of the cost of children turns around $22-24 \%$ of the total expenditure of the household, which is much more conform to intuition than traditional evaluations based on the Rothbarth method.

The paper is structured as follows. In Section 2, we describe the model and demonstrate how it can be identified. In Section 3, we present the functional form and the method of estimation. We present the data and report the results in Section 4 . Section 5 concludes. 


\section{The Model}

\subsection{Preferences, Technologies and the Decision Process}

We consider three types of households, namely, a single individual $(n=1)$, a couple without children $(n=2)$ and a couple with one child $(n=3)$. Individuals are indexed by subscript $j$ while superscript $k=1, \ldots, K$ denotes goods. By convention, we suppose that $j=1$ is a male adult, $j=2$ is a female adult and $j=3$ is a child. The $\log$ total expenditure in a household is denoted by $x$ and the vector of log prices by $\boldsymbol{p}$. The indirect utility function of a single individual $j$ endowed with $\log$ resources $x$ is supposed to be well-behaved (monotonic, strictly quasi-convex, and twice-continuously differentiable) and is denoted by $v_{j}(\boldsymbol{p}, x)$. The "basic" budget share of individual $j$ for good $k$ is then defined by

$$
w_{j}^{k}(\boldsymbol{p}, x)=-\frac{\partial v_{j}(\boldsymbol{p}, x) / \partial p^{k}}{\partial v_{j}(\boldsymbol{p}, x) / \partial x}
$$

that is, if person $j$ was living alone, and if he/she maximized his/her utility function subject to a budget constraint, he/she would spend the fraction $w_{j}^{k}(\boldsymbol{p}, x)$ of total expenditure $\exp (x)$ on good $k$. If he/she is living with other persons, his/her "basic" budget share equations will change in a way that reflects scale economies and resource sharing, as further explained below.

In a multi-person household $(n>1)$, we first assume that total expenditure $\exp (x)$ is divided between household members according to some rule. Precisely, individual $j$ living in household of type $n$ receives a resource share $\eta_{j, n}(\boldsymbol{p}, x)$ of total expenditure $\exp (x)$. We do not specify the decision process, unitary or collective, that determines these shares but suppose they may, in general, depend on prices and total expenditure. ${ }^{3}$ The shares of all members are differentiable comprised between zero and one; they sum up to unity, i.e., $\sum_{j=1}^{n} \eta_{j, n}(\boldsymbol{p}, x)=1$. To obtain our main results, we also adopt the same assumption

\footnotetext{
${ }^{3}$ For instance, we can imagine that the resources accruing to the child vary with the price of child goods (such as child's clothing or toys); see also Bargain and Donni (2008) on this point.
} 
as Lewbel and Pendakur (2008), that is:

A.1. The shares of expenditure do not depend on total household expenditure $x$, that is, $\eta_{j, n}(x, \boldsymbol{p})=\eta_{j, n}(\boldsymbol{p})$ for $j=1,2,3$ and $n=2,3$.

This assumption is potentially strong. It is likely however that identification can be achieved without it - we keep this for future research. Moreover, this assumption can be mitigated in empirical applications by including measures of household wealth other than total expenditure in income shares. Our objective here is simply to keep the empirical model simple and tractable at the expense of reasonable approximations.

Moreover, we assume that economies of scale and scope generated by joint consumption of certain goods in the household can be represented by the independence of base (IB) assumption. We introduce it formally below:

A.2. (I.B.) For each person $j$ living in a household of type $n>1$, we assume that there exists a scalar-valued, differentiable function $s_{j, n}(\boldsymbol{p})$ such that the indifference curves of individual $j$ satisfy the condition:

$$
u_{j}=v_{j}\left(\boldsymbol{p}, x+\log \eta_{j, n}(\boldsymbol{p})-\log s_{j, n}(\boldsymbol{p})\right)
$$

for any level of $\log$ individual expenditure $x+\log \eta_{j, n}(\boldsymbol{p})$.

To unify our notation, we also set $\eta_{j, 1}(\boldsymbol{p})=s_{j, 1}(\boldsymbol{p})=1$ for a single individual $(n=1)$. Intuitively, equation (1) means that economies of scale can be summarized by a simple income effect represented by the price-dependent deflator $s_{j, n}(\boldsymbol{p})$. The latter measures the cost savings experienced by person $j$ resulting from scale economies in the household. The IB assumption refers to the fact that scale economies are assumed to be independent of the base expenditure (and hence utility) level at which they are evaluated. This assumption is similar to the IB restriction in the equivalence scale literature, but it concerns individual utility functions rather than aggregated household utility functions. Whereas the 
traditional equivalence scale literature restricts how indirect utility responds to changes in demographic characteristics, equation (1) only restricts how an individual's indirect utility responds to the changes in the shadow prices of consumption resulting from economies of scale. ${ }^{4}$ The fact that $s_{j, n}(\boldsymbol{p})$ depends on prices makes the IB scale far more general than traditional Engel scales; in particular, the idea that some goods are consumed in common (and thereby largely affected by economies of scale) while other goods are not can be represented here by the derivative of $s_{j, n}(\boldsymbol{p})$ with respect to prices. ${ }^{5}$ The economies of scale may also differ between individuals within the same household, depending on how they value the good which is jointly consumed. Note also that IB scales can be seen as an approximation of Barten scales (used by Browning, Chiappori and Lewbel, 2008) in the sense that demands can be both IB and Barten scaled if at least one linear restriction exists on the log of Barten scales (Lewbel, 1991).

Denote $\log I_{j, n}(\boldsymbol{p})=\log s_{j, n}(\boldsymbol{p})-\log \eta_{j, n}(\boldsymbol{p})$ so that equation (1) can be compactly written as:

$$
u_{j}=v_{j}\left(\boldsymbol{p}, x-\log I_{j, n}(\boldsymbol{p})\right)
$$

The term $I_{j, n}$ is member $j$ 's indifference scale as defined by Lewbel (2003) and Browning, Chiappori and Lewbel (2008). This concept differs from an ordinary equivalence scale, which attempts to compare the welfare of an individual to that of a household, and hence suffers from the fundamental identification problem associated with interpersonal comparisons (Pollak and Wales, 1979, 1992). In contrast, an indifference scale can be seen as comparing the same individual in two different situations: living alone and living with a

\footnotetext{
${ }^{4}$ The former is untestable while the latter can in principle be tested. See Lewbel $(1989,1991)$, Blundell and Lewbel (1990), Blackorby and Donaldson (1990), Pendakur (1999).

${ }^{5}$ To take a loosy example, let us suppose that good $k$ is associated with relatively important economies of scale (like shelter). Hence, if the price of good $k$ is very high so that the consumption of this good is small, the total economies of scale, represented here by the deflator $s_{j, n}(\boldsymbol{p})$ for member $j$, will remain limited. However, if the price of good $k$ decreases, enhancing the consumption of this good, then the economies of scale will become more and more important, and $s_{j, n}(\boldsymbol{p})$ will decrease.
} 
partner (with or without children). It represents the income adjustment applied to person $j$ when living alone for her/him to reach the same indifference curve as when living in a multi-person household, consuming a share $\eta_{j, n}$ of total resources and benefiting from scale economies represented by $s_{j, n}$. Implicitly, the direct utility or disutility from living with others (such as love and companionship) is assumed to be separable from consumption goods. Moreover, the couple's economies of scale can be defined as the scalar by which the total expenditure of a couple should be multiplied for there exists a division of this total expenditure such that the two persons obtain the same level of utility alone as when in a couple. Denote $s_{n}(\boldsymbol{p})=\sum_{j=1,2} s_{j, n}(\boldsymbol{p})$ the share of total expenditure devoted to adults (which is equal to one in childless couples). The couple's economies of scale can be computed as the sum of the inverse of indifference scales,

$$
E_{n}(\boldsymbol{p})=s_{n}(\boldsymbol{p}) \times \sum_{j=1,2}\left[I_{j, n}(\boldsymbol{p})\right]^{-1}=\sum_{j=1,2} \frac{\eta_{j, n}(\boldsymbol{p})}{s_{j, n}(\boldsymbol{p}) / s_{n}(\boldsymbol{p})} .
$$

Finally, note that with Assumption A.1, indifference scales as well as scale economies are independent of the base - a property which is often imposed in the traditional equivalent scales literature.

Denoting the $\log$ individual share as $x_{j, n}(\boldsymbol{p}, x)=x+\log \eta_{j, n}(\boldsymbol{p})$ and applying Roy's identity to equation (1), individual $j$ 's budget share function for good $k$ is defined as:

$$
\omega_{j, n}^{k}(\boldsymbol{p}, x)=-\frac{\partial v_{j}\left(\boldsymbol{p}, x_{j, n}(\boldsymbol{p}, x)-\log s_{j, n}(\boldsymbol{p})\right) / \partial p^{k}}{\partial v_{j}\left(\boldsymbol{p}, x_{j, n}(\boldsymbol{p}, x)-\log s_{j, n}(\boldsymbol{p})\right) / \partial x_{j, n}},
$$

where the left-hand side of this expression is the fraction of member $j$ 's share, $\exp (x) \times$ $\eta_{j, n}(\boldsymbol{p})$, spent on good $k$. Developing the derivatives, it is easy to show that

$$
\omega_{j, n}^{k}(\boldsymbol{p}, x)=d_{j, n}^{k}(\boldsymbol{p})+w_{j}^{k}\left(\boldsymbol{p}, x-\log I_{j, n}(\boldsymbol{p})\right)
$$

where

$$
d_{j, n}^{k}(\boldsymbol{p})=\frac{\partial \log s_{j, n}(\boldsymbol{p})}{\partial p^{k}}
$$

is the elasticity of $s_{j, n}(\boldsymbol{p})$ with respect to the $k$-th price. The consequence of the IB assumption in the present context is that the budget share equations of person $j$ when 
living in a household differ from when alone only in that they are translated over log household resources $x$ by $\log I_{j, n}(\boldsymbol{p})$ and over each $w_{j}^{k}(\cdot)$ by $d_{j, n}^{k}(\boldsymbol{p})$. This property is referred to as shape invariance by Pendakur (1999). The translation function $d_{j}^{k}(\boldsymbol{p})$ is specific to good $k$ and related to the differences that may exist between goods with respect to the possibility of joint consumption.

We now suppose that data are observed in a unique price regime, as provided in crosssectional data, so that the vector of prices $\boldsymbol{p}$ is constant and can be taken out of equation (3). Although scale economies do not depend on the base expenditure, they may vary with the demographic structure of the household. Thus, a vector $z$ of household sociodemographic variables is introduced in equation (3). Formally, the implications of the IB assumption in a framework with no price variation are described in the following lemma:

Lemma 1. Assume A.1 and A.2. Then, the budget share of good $k$ of person $j$ living in household of type $n$ is written:

$$
\omega_{j, n}^{k}(x, \boldsymbol{z})=d_{j, n}^{k}(\boldsymbol{z})+w_{j}^{k}\left(x-\log I_{j, n}(x, \boldsymbol{z}), \boldsymbol{z}_{j}\right)
$$

where $\log I_{j, n}(x, \boldsymbol{z})=\log s_{j, n}(\boldsymbol{z})-\log \eta_{j, n}(x, \boldsymbol{z})$ is the $\log$ deflator of total expenditure which combines the scaling effect $s_{j, n}$ and resource sharing $\eta_{j, n}$.

Proof. Straightforward from equation (3). ॥

The left-hand side of equation (4) represents the 'reduced-form' budget share of person $j$ on good $k$ as a function of $(\log )$ household resources $x$ and household characteristics $\boldsymbol{z}$. The right-hand side puts some structure on the budget share as a result of the IB restriction. The individual budget share function $w_{j}^{k}(\cdot)$ depends on person $j$ 's individual resources adjusted by the scaling factor $s_{j, n}(\boldsymbol{z})$ and on individual characteristics $\boldsymbol{z}_{j}$; this share is then translated by the price elasticity of scale economies. The scaling effect $s_{j, n}(\boldsymbol{z})$, and subsequently its price elasticity $d_{j, n}^{k}(\boldsymbol{z})$, generally depend on all the individual characteristics of persons living in the household $\boldsymbol{z}$. Indeed, in all generality, we cannot 
exclude that the extent of joint consumption be related to the characteristics of all the persons living in the household. The resource share $\eta_{j, n}(\boldsymbol{z})$ depends on the vector of household characteristics $z$ and may also incorporate specific variables that govern the resource sharing rule (that is, distribution factors, according to the traditional terminology of Bourguignon, Browning, and Chiappori, 2008). ${ }^{6}$ A possible candidate for these variables candidate for these variables is the ratio of spouses' exogenous incomes in as much as the household bargaining power of spouses depends on what they earn.

For each good $k$, we can write total household expenditure as the sum of individual expenditures on that good. Dividing this identity by total outlay $\exp (x)$, we obtain directly the household budget share function for good $k$ :

$$
W_{n}^{k}(x, \boldsymbol{z})=\sum_{j=1}^{n} \eta_{j, n}(\boldsymbol{z}) \cdot \omega_{j, n}^{k}(x, \boldsymbol{z}) .
$$

where $W_{n}^{k}(\cdot)$ is the share spent by the type- $n$ household on good $k$. This is simply the sum of individual budget share equations over all household members, weighted by their individual resource shares. Using equation (4), this can be written as:

$$
W_{n}^{k}(x, \boldsymbol{z})=\sum_{j=1}^{n} \eta_{j, n}(\boldsymbol{z})\left[d_{j, n}^{k}(\boldsymbol{z})+w_{j}^{k}\left(x-\log I_{j, n}(\boldsymbol{z}), \boldsymbol{z}_{j}\right)\right]
$$

where individual budget shares are translated both in budget shares and log-expenditure. One word of reservation is needed here. Changes in the demographic structure of the household may also generate modification of preferences and externalities in consumption that are not explicitly accounted for by the IB assumption. Note that the model of Lewbel and Pendakur (2008) exhibits basically the same problem even if it is perhaps more critical as soon as children are incorporated in the analysis. In particular, the apparition of a child in the household may generate important externalities. For example, the parents may decide stop smoking and to change their leisure activities. Whether the

\footnotetext{
${ }^{6}$ Logically, the distribution factors do not enter scale economies because they influence behavior only via the intra-household distribution of total expenditure
} 
deflator $s_{j, n}(\boldsymbol{z})$ can conveniently represent modifications of preferences and externalities in consumption is a complicated question which is beyond the scope of the present paper. If the answer is negative, however, the interpretation of the empirical results we make may be biased. We have to keep in mind these potential limitations of the model.

\subsection{Identification Strategy}

Our goal here is to identify the important structural elements of the model, namely resource shares $\eta_{j, n}(\boldsymbol{z})$ and scale economies $s_{j, n}(\boldsymbol{z})$, from demand data. To begin with, we add stochastic terms to the household budget shares previously defined:

$$
W_{n}^{k}(x, \boldsymbol{z})=\sum_{j=1}^{n} \eta_{j, n}(\boldsymbol{z}) \cdot\left[d_{j, n}^{k}(\boldsymbol{z})+w_{j}^{k}\left(x-\log I_{j, n}(x, \boldsymbol{z}), \boldsymbol{z}_{j}\right)\right]+\varepsilon_{n}^{k}
$$

The classic interpretation of the stochastic term $\varepsilon_{n}^{k}$ is that it represents optimization or measurement errors. Alternatively, the stochastic component could be interpreted as resulting from unobservable heterogeneity in tastes (entering utility functions), in economies of scale and in the intra-household distribution of expenditure. For instance, if the elasticities of scales with respect to prices are random, then $\varepsilon_{n}^{k}=\sum_{j=1}^{n} \eta_{j, n}(\boldsymbol{z}) \cdot \varepsilon_{j, n}^{k}$, where $\varepsilon_{j, n}^{k}$ is an idiosyncratic term for member $j$ in the household. In that case, the term $\varepsilon_{n}^{k}$ will generally be heteroscedastic.

Identification exploits the following additional assumption:

A.3. There exists at least one adult-specific good $k$ (say), that is, a good which is consumed by parents but not by children.

The concept of adult-specific goods plays a major role in a well-known method used to measure the cost of children and referred to as the Rothbarth method. Classic examples of adult-specific goods include certain pieces of clothing, tobacco and alcohol. The adultspecific good can be consumed by both parents, it has not to be specific to the mother or the father. The main result is then summarized in the following proposition. 
Proposition 2. Assume A.1, A.2 and A.3. Then, the resource shares $\eta_{j, n}(x, \boldsymbol{z})$ and the scale economies $s_{j, n}(x, \boldsymbol{z})$, for $j=1,2,3$, can be identified from the estimation of the budget share equations $W_{n}^{k}(x, \boldsymbol{z})$ for the adult-specific good $k$, with $n=1,2,3$.

The proof follows in stage. We first discuss how to retrieve the "basic" budget share equations. We then consider identification in the case of couples without child and in the case of couples with one child. First, we have:

$$
\eta_{j, 1}(\boldsymbol{z}, x)=1, \quad d_{j, 1}^{k}(\boldsymbol{z})=0, \quad s_{j, 1}(\boldsymbol{z})=1
$$

for single men $(j=1)$ or single women $(j=2)$, so that single individuals are used as the demographic structure of reference. The budget share equations of a single-person household for all goods $k=1, \ldots K$ boil down to:

$$
W_{1}^{k}(x, \boldsymbol{z})=w_{j}^{k}\left(x, \boldsymbol{z}_{j}\right)+\varepsilon_{1}^{k}
$$

These equations can be identified from well-known results in non-parametric econometrics provided that the sample is sufficiently large and that the stochastic term satisfies some normalization restrictions. The additivity of the stochastic term on the right-handside makes things simpler because, in that case, identifying the budget share function is analogous to identifying its conditional expectation function. ${ }^{7}$

To retrieve the main structural components of the model, the basic idea is that differences between an individual's bundle of goods consumed as a single versus within a household are assumed to be due to partially joint consumption, resource sharing and to changes in total resources, but are not attributed to unobservable taste change. As argued by Gronau (1988), this assumption, as strong as it may seem, is necessary to make the comparison of individuals living in different households possible.

We now consider the case of a childless couple, that is, $n=2$. The household budget

\footnotetext{
${ }^{7}$ This assumption is not essential, though, as indicated by some results in non parametric econometrics (provided that the stochastic term in each equation is unique (Matzkin, 2007)).
} 
share equation for good $k$ can be written as:

$$
W_{2}^{k}(x, \boldsymbol{z})=\sum_{j=1}^{2} \eta_{j, 2}(\boldsymbol{z}) \cdot\left[d_{j, 2}^{k}(\boldsymbol{z})+w_{j}^{k}\left(x-\log I_{j, 2}(\boldsymbol{z}), \boldsymbol{z}_{j}\right)\right]+\varepsilon_{2}^{k} .
$$

The following lemma is, in fact, a reformulation of a result obtained by Lewbel and Pendakur (2008).

Lemma 3. Assume A.1, A.2 and $n=2$. Then, the functions $s_{j, 2}(\boldsymbol{z}), \eta_{j, 2}(\boldsymbol{z})$, with $j=$ 1,2 , are generically identified from the knowledge of the functions $w_{j}^{k}\left(\cdot, \boldsymbol{z}_{j}\right)$, with $j=1,2$, and the estimation of the budget share equation $W_{2}^{k}(x, \boldsymbol{z})$ for good $k$.

Proof. To eliminate the constant $d_{j, 2}^{k}(\boldsymbol{z})$ from equation (9), we compute the first order derivative of this expression with respect to $x$ and obtain:

$$
\nabla_{x} W_{2}^{k}(x, \boldsymbol{z})=\sum_{j=1}^{2} \eta_{j, 2}(\boldsymbol{z}) \nabla_{x} w_{j}^{k}\left(x+\log \eta_{j, 2}(\boldsymbol{z})-\log s_{j, 2}(\boldsymbol{z}), z_{j}\right),
$$

where the left-hand side of this expression is identified from traditional results in econometrics. This equation generically defines the functions $\eta_{j, 2}(\boldsymbol{z})$ and $s_{j, 2}(\boldsymbol{z})$, with $j=1,2$. To show this, let us consider a set of three observations $\left\{\left(x_{T}, \boldsymbol{z}_{T}\right) \mid T=1,2,3\right\}$ such that $x_{T}$ varies within its domain and $\boldsymbol{z}_{T}$ is maintained constant and equal to some arbitrary value $\overline{\boldsymbol{z}}$. Noting that $\eta_{1,2}(\boldsymbol{z})+\eta_{2,2}(\boldsymbol{z})=1$, there are three unknowns. For each observation, there is one equation:

$$
\nabla_{x} W_{2}^{k}\left(x_{T}, \overline{\boldsymbol{z}}\right)=\sum_{j=1}^{2} \eta_{j, 2}(\overline{\boldsymbol{z}}) \cdot \nabla_{x} w_{j}^{k}\left(x_{T}+\log \eta_{j, 2}(\overline{\boldsymbol{z}})-\log s_{j, 2}(\overline{\boldsymbol{z}}), \overline{\boldsymbol{z}}_{j}\right),
$$

for $T=1,2,3$. Then, counting equations and unknowns, we note that the system of equations defines the values $\eta_{j, 2}(\overline{\boldsymbol{z}})$ and $s_{j, 2}(\overline{\boldsymbol{z}})$ for any arbitrary value $\overline{\boldsymbol{z}}$. Once these functions are recovered, the constant can be identified from:

$$
\sum_{j=1}^{2} \eta_{j, 2}(\boldsymbol{z}) d_{j, 2}^{k}(\boldsymbol{z})=W_{2}^{k}(x, \boldsymbol{z})-\sum_{j=1}^{2} \eta_{j, 2}(\boldsymbol{z}) w_{j}^{k}\left(x-I_{j, 2}(\boldsymbol{z}), \boldsymbol{z}_{j}\right),
$$


which identifies the left-hand side. Note that the functions $d_{j, 2}^{k}(\boldsymbol{z})$ could be separately identified if there were distribution factors that affect the distribution of resources without affecting scale economies.\|

This result is only generic in the sense that it is 'almost always' satisfied in the traditional mathematical sense. Still it is possible for arbitrary preferences that it is violated. For instance, it is clear that the structural components are not identifiable if the budget share equation for good $k$ is linear in its first argument. Formally, this result requires the knowledge of the budget share equations, $w_{1}^{k}\left(\cdot, \boldsymbol{z}_{j}\right), w_{2}^{k}\left(\cdot, \boldsymbol{z}_{j}\right)$ and $W_{2}^{k}(x, \boldsymbol{z})$, for one good only. Nonetheless, it is clear enough that further goods will improve identification and generate over-identification restrictions.

In a further step, we consider the case of a couple with one child. The budget share equations can be written as:

$$
W_{3}^{k}(x, \boldsymbol{z})=\sum_{j=1}^{3} \eta_{j, 3}(\boldsymbol{z}) \cdot\left[d_{j, 3}^{k}(\boldsymbol{z})+w_{j}^{k}\left(x-I_{j, 3}(\boldsymbol{z}), \boldsymbol{z}_{j}\right)\right]+\varepsilon_{3}^{k} .
$$

Here, one problem is that the budget share equations of the child, $w_{3}^{k}(\cdot)$, cannot be directly obtained from a sample of single families as it was the case for mother and father's budget share equations. Moreover, it must be clear that the terms representing economies of scale, $d_{j, 3}^{k}(\cdot)$ and $s_{j, 3}(\cdot)$, cannot be disentangled from the budget share equations, $w_{3}^{k}(\cdot)$. Potential scale economies for children are implicitly incorporated in preferences (just as it is for adults in models where scale economies are not explicitly modeled). However, these terms are actually meaningless concepts in a world where young children never live alone. Hence, without loss of generality, we can normalize these terms:

$$
d_{j, 3}^{k}(\boldsymbol{z})=0, \quad s_{j, 3}(\boldsymbol{z})=0 .
$$

To show how identification can be attained, let us suppose that good $k$ is an adult-specific good so that its budget share function is given by

$$
W_{3}^{k}(x, z)=\sum_{j=1}^{2} \eta_{j, 3}(\boldsymbol{z})\left[d_{j, 3}^{k}(\boldsymbol{z})+w_{j}^{k}\left(x-I_{j, 3}(\boldsymbol{z}), \boldsymbol{z}_{j}\right)\right]+\varepsilon_{3}^{k} .
$$


The following lemma then indicates what can be identified.

Lemma 4. Assume A.1, A.2, A.3 and $n=3$. Then, the functions $s_{j, 3}(\boldsymbol{z}), \eta_{j, 3}(\boldsymbol{z})$, with $j=$ 1,2 , are generically identified from the knowledge of the functions $w_{j}^{k}\left(\cdot, \boldsymbol{z}_{j}\right)$, with $j=1,2$, and the estimation of the budget share equation $W_{3}^{k}(x, \boldsymbol{z})$ for an adult-specific good $k$.

Proof. The functions $s_{j, 3}(z)$ and $\eta_{j, 3}(z)$ can be identified according to the same methodology as previously. To sum up, the equation above is derived with respect to $x$ to eliminate $d_{j, 3}^{k}(\boldsymbol{z})$ and then, the functions $\eta_{j, 3}(\boldsymbol{z})$ and $s_{j, 3}(\boldsymbol{z})$ for $j=1,2$ can be identified, using equation (10), from a set of 4 observations at least. Then, the resource share of the child can be obtained as:

$$
\eta_{3,3}(\boldsymbol{z})=1-\sum_{j=1}^{2} \eta_{j, 3}(\boldsymbol{z}) .
$$

This lemma completes the proof of Proposition 1.

\section{Empirical Implementation}

\subsection{Functional Form}

For the estimation, we suggest a parameterization that balances flexibility and empirical tractability. The first component, which appears in the specification of the different demographic groups, is the "basic" budget share equation. Following the recent recognition that a quadratic specification is generally necessary to model budget shares (Banks, Blundell, and Lewbel, 1997), we adopt the following functional form:

$$
w_{j}^{k}\left(\phi, \boldsymbol{z}_{j}\right)=a_{j}^{k}+\mathbf{a}_{j}^{k \prime} \boldsymbol{z}_{j}+b_{j}^{k}\left(\phi-\mathbf{e}_{j}^{\prime} \boldsymbol{z}_{j}\right)+c_{j}^{k}\left(\phi-\mathbf{e}_{j}^{\prime} \boldsymbol{z}_{j}\right)^{2},
$$

for $j=1,2,3$ and $k=1, \ldots, K$, where $\phi$ is a given level of log scaled individual expenditures (equal to $x$ for a single $n=1$ and to $x-\log I_{j, n}(\boldsymbol{z})$ for individual $j$ in a family $n=2,3), a_{j}^{k}, b_{j}^{k}, c_{j}^{k}$ are parameters, and $\mathbf{a}_{j}^{k}$ and $\mathbf{e}_{j}$ are vectors of parameters. The vectors 
of adult characteristics $z_{1}$ and $z_{2}$ include a dummy "age above 40", a dummy "tertiary education", and dummies for "car ownership" and "urban resident". The parameters are gender specific (i.e., are indexed $j=1$ for men and $j=2$ for women) but do not depend on the demographic type $n$ since the "basic" budget share equations are the same for single women (men) and for women (men) living in a couple. For children, the vector $z_{3}$ includes a dummy "female" in order to differentiate the cost of boys and girls and a dummy "age below 2" to reflect differences in children's age.

We now turn to the specification of the household budget share equations. For single male and female adults, they coincide with the "basic" budget share equations specified above plus an additive stochastic term, that is,

$$
W_{1}^{k}(x, \boldsymbol{z})=w_{j}^{k}\left(x, \boldsymbol{z}_{j}\right)+\varepsilon_{1}^{k}
$$

For multi-person households $n \geq 2$, and for non-adult-specific goods, the household budget share equations,

$$
W_{n}^{k}(x, \boldsymbol{z})=\sum_{j=1}^{n} \eta_{j, n}(\boldsymbol{z})\left[d_{j, n}^{k}(\boldsymbol{z})+w_{j}^{k}\left(x-\log I_{j, n}(\boldsymbol{z}), \boldsymbol{z}_{j}\right)\right]+\varepsilon_{n}^{k}
$$

comprise the individual functions $w_{j}^{k}\left(\cdot, \boldsymbol{z}_{j}\right)$ as already specified and three other components that are defined as follows. Firstly, the resource shares are specified using the logistic form:

$$
\eta_{j, n}(\boldsymbol{z})=\frac{\exp \left(\boldsymbol{\varphi}_{j, n}^{\prime} \boldsymbol{z}_{j}^{*}\right)}{\sum_{j=1}^{n} \exp \left(\boldsymbol{\varphi}_{j, n}^{\prime} \boldsymbol{z}_{j}^{*}\right)}
$$

where $\boldsymbol{\varphi}_{j, n}$ is a vector of parameters. The parameters of women $j=2$ are set to zero for normalization. To limit the number of parameters, vector $z_{j}^{*}$ includes the sets of individual characteristics $\boldsymbol{z}_{j}$ for $j=1, \ldots n$ and a distribution factor - the wage ratio which is defined as the ratio of wife's over husband's earnings expressed in full-time equivalent - but it does not include individual characteristics of the partner. Note also that, from the property of the logistic function, the respective effect of children on the mother's and the father's 
share is proportionate. Secondly, the log scale function that translates expenditure within the basic budget shares can be written as:

$$
\log s_{j, n}(\boldsymbol{z})=\beta_{j, n}+\boldsymbol{\beta}_{j} \boldsymbol{z}_{j}
$$

for $j=1,2$, where $\beta_{j, n}$ and $\boldsymbol{\beta}_{j}$ are parameters and vector of parameters. In principle, scale economies can vary with all the variables used in preferences (i.e., $\boldsymbol{z}_{j}$ for $j=1, \ldots, n$ ) but it is restricted to depend only on parameters of member $j$. To limit the number of parameters, only the constant is indexed by the type of family. Finally, the scale function that translates the basic budget shares $d_{j, n}^{k}(\boldsymbol{z})$ is a price elasticity. Measuring price effects is generally challenging and it is all the more difficult to capture their interaction with demographics in any plausible way. Moreover, the translation terms are not robustly identified. Therefore we restrict these terms to be constant, that is:

$$
d_{j, n}^{k}(\boldsymbol{z})=d_{j, n}^{k}
$$

\subsection{Estimation Method}

The complete model is estimated by the iterated SURE method. To account for the

likely correlation between the error terms $\varepsilon_{n}^{k}$ in each budget share function and the log total expenditure, each budget share equation is augmented with the errors $\hat{v}_{n}^{1}$ and $\hat{v}_{n}^{2}$ obtained from reduced-form estimations, specific to family type $n$, of $x$ and $x^{2}$ respectively on all exogenous variables used in the model plus some excluded instruments (Smith and Blundell, 1986; Blundell and Robin, 1999, 2000; Banks, Blundell and Lewbel, 1997). For the latter, we choose a fourth order polynomials in log household disposable income and the inverse of the disposable income. Since budget shares sum up to one, equation for good $K$ is unnecessary. The household budget share equations for the $K-1$ goods and for the three demographic groups are estimated simultaneously. The stochastic terms are supposed to be uncorrelated across households but correlated across goods within households. They are supposed to be homoscedastic for each family type $n$ (and covariance 
matrices are supposed to be different for single male and female). Observations in the data are indexed by $h$ and the number of singles, couples without children, and couples with children in the data is denoted by $H_{1}, H_{2}$, and $H_{3}$, respectively. Let $\mathbf{W}_{n, h}$ be the $(K-1)$ vector of observed budget shares for the first $K-1$ goods consumed by household $h$ of type $n$ and let $\hat{\mathbf{W}}_{n, h}(\boldsymbol{\theta})$ be the corresponding $(K-1)$ vector of predicted budget shares for a parameter vector $\boldsymbol{\theta}$. The vector of residuals is thus given by $\boldsymbol{\varepsilon}_{n, h}(\boldsymbol{\theta})=\mathbf{W}_{n, h}-\hat{\mathbf{W}}_{n, h}(\boldsymbol{\theta})$. If

$\hat{\boldsymbol{\varepsilon}}_{n, h}=\boldsymbol{\varepsilon}_{n, h}\left(\hat{\boldsymbol{\theta}}_{0}\right)$, where $\hat{\boldsymbol{\theta}}_{0}$ is any initial consistent estimation of the vector of parameters, the estimated covariance matrix can be defined by

$$
\hat{\mathbf{V}}_{n}=H_{n}^{-1} \times\left(\hat{\varepsilon}_{n, h}\right)\left(\hat{\varepsilon}_{n, h}\right)^{\prime}
$$

The SURE criterion is then:

$$
\min _{\boldsymbol{\theta}} \sum_{n=1}^{3} \sum_{h=1}^{H_{n}}\left(\boldsymbol{\varepsilon}_{n, h}(\boldsymbol{\theta})\right)^{\prime}\left(\hat{\mathbf{V}}_{n}\right)^{-1}\left(\boldsymbol{\varepsilon}_{n, h}(\boldsymbol{\theta})\right),
$$

which gives a new value $\hat{\boldsymbol{\theta}}_{1}$ for the estimates. The estimation procedure is then iterated with the new estimates until the covariance matrix converges.

\section{Data and Empirical Results}

\subsection{Data and Sample Selection}

Our sample is drawn from the 2000 French Household Budget Survey conducted by INSEE. This data gathers information on household expenditures, incomes and sociodemographics for 10,350 representative households. It was collected over the year 2000 and only little price variation is witnessed over this period so that the sample can be treated as cross-sectional data. All household members who are at least 14 years of age are interviewed. Durable goods are recorded for the past year, health and holidays expenditures are for the past 6 months, clothing is for the past two months, consumption of daily services and goods are recorded in diaries over the 14 days of the study. 
Our selection criterion is as follows. To begin with, we exclude households larger than the nucleus family (parents, children), with more than one child or where the child is aged 14 or more (and hence not differentiable from adults in terms of clothing expenditure in the data), which leaves out about $38 \%$ of the sample. We then select households where adults are aged 18-59, which further restricts the initial sample by $26 \%$ and we withdraw another $2 \%$ corresponding to households where adults are students, in the army or retired (most of this selection is already done through the age limits). Since leisure is not modeled here, but is likely endogenous to consumption (and savings) decisions, we finally restrict our sample to working adults and full-time working men. This excludes another $13 \%$ of the original sample, $7 \%$ of which is due to non-participating spouses in couples. The final sample is composed of 2,155 observations and is described in Table 1.

In the estimation process, we consider a system of $K=10$ non-durable commodities: food (in and out), "vice" goods (alcohol, tobacco and gambling), male, female and child clothing, transport, leisure, household operation, personal goods and services and housing (the omitted good in the Engel curve system). ${ }^{8}$ In the original data, a marginal proportion of single women reports nonzero expenditures on male clothing; the same occurs with expenditures on female clothing by single men or expenditures on children by childless households. These expenditures are interpreted as gifts and, in order to treat clothing as an assignable good, they are not considered (indeed the motivation of gifts is completely different from that of direct consumption). Formally, one male-specific good and one female-specific good is more than what we need to identify the main components of the model. To improve estimations, however, we also suppose that expenditures on vice goods are adult-specific while expenditures on child clothing are child-specific.

\footnotetext{
${ }^{8}$ Traditionally, expenditures on housing are not modeled (because these expenditures may be difficult to evaluate for owners). Nonetheless, we believe that expenditure on housing cannot be ignored when economies of scale are considered. In doing so, we must mention that the size of the household may be endogenous in making housing decisions.
} 


\begin{tabular}{|c|c|c|c|c|}
\hline & $\begin{array}{c}\text { Single } \\
\text { women }\end{array}$ & $\begin{array}{c}\text { Single } \\
\text { men }\end{array}$ & $\begin{array}{l}\text { Childless } \\
\text { couples }\end{array}$ & $\begin{array}{c}\text { Couples \& } 1 \\
\text { child }\end{array}$ \\
\hline Age (male) & - & $\begin{array}{c}0.41 \\
(0.49)\end{array}$ & $\begin{array}{c}0.56 \\
(0.50)\end{array}$ & $\begin{array}{c}0.21 \\
(0.41)\end{array}$ \\
\hline Age (female) & $\begin{array}{c}0.45 \\
(0.50)\end{array}$ & - & $\begin{array}{c}0.52 \\
(0.50)\end{array}$ & $\begin{array}{c}0.14 \\
(0.35)\end{array}$ \\
\hline Education (male) & - & $\begin{array}{c}0.37 \\
(0.48)\end{array}$ & $\begin{array}{c}0.29 \\
(0.46)\end{array}$ & $\begin{array}{c}0.30 \\
(0.46)\end{array}$ \\
\hline Education (female) & $\begin{array}{c}0.46 \\
(0.50)\end{array}$ & - & $\begin{array}{c}0.34 \\
(0.47)\end{array}$ & $\begin{array}{c}0.40 \\
(0.39)\end{array}$ \\
\hline Urban & $\begin{array}{c}0.90 \\
(0.29)\end{array}$ & $\begin{array}{c}0.84 \\
(0.37)\end{array}$ & $\begin{array}{c}0.77 \\
(0.42)\end{array}$ & $\begin{array}{c}0.74 \\
(0.44)\end{array}$ \\
\hline Car & $\begin{array}{c}0.78 \\
(0.42)\end{array}$ & $\begin{array}{c}0.81 \\
(0.39)\end{array}$ & $\begin{array}{c}0.96 \\
(0.19)\end{array}$ & $\begin{array}{c}0.97 \\
(0.18)\end{array}$ \\
\hline Wage ratio & - & - & $\begin{array}{c}0.84 \\
(0.68)\end{array}$ & $\begin{array}{c}0.88 \\
(1.16)\end{array}$ \\
\hline Total Expenditure (EUR/week) & $\begin{array}{c}289 \\
(126)\end{array}$ & $\begin{array}{c}304 \\
(160)\end{array}$ & $\begin{array}{l}495 \\
(255)\end{array}$ & $\begin{array}{l}540 \\
(262)\end{array}$ \\
\hline Child's sex & - & - & - & $\begin{array}{c}0.49 \\
(0.50)\end{array}$ \\
\hline Child's age & - & - & - & $\begin{array}{c}0.47 \\
(0.50) \\
\end{array}$ \\
\hline \multicolumn{5}{|l|}{ Budget shares: } \\
\hline Food & $\begin{array}{c}0.20 \\
(0.09)\end{array}$ & $\begin{array}{c}0.21 \\
(0.10)\end{array}$ & $\begin{array}{c}0.23 \\
(0.09)\end{array}$ & $\begin{array}{c}0.25 \\
(0.09)\end{array}$ \\
\hline Vices & $\begin{array}{c}0.03 \\
(0.04)\end{array}$ & $\begin{array}{l}0.05 \\
(0.08)\end{array}$ & $\begin{array}{c}0.04 \\
(0.05)\end{array}$ & $\begin{array}{l}0.03 \\
(0.04)\end{array}$ \\
\hline Transport & $\begin{array}{c}0.11 \\
(0.09)\end{array}$ & $\begin{array}{c}0.14 \\
(0.12)\end{array}$ & $\begin{array}{c}0.13 \\
(0.08)\end{array}$ & $\begin{array}{c}0.13 \\
(0.09)\end{array}$ \\
\hline Leisure Goods \& Services & $\begin{array}{c}0.09 \\
(0.07)\end{array}$ & $\begin{array}{c}0.10 \\
(0.10)\end{array}$ & $\begin{array}{c}0.10 \\
(0.08)\end{array}$ & $\begin{array}{l}0.10 \\
(0.07)\end{array}$ \\
\hline Household Operations & $\begin{array}{c}0.05 \\
(0.06)\end{array}$ & $\begin{array}{c}0.04 \\
(0.07)\end{array}$ & $\begin{array}{c}0.07 \\
(0.08)\end{array}$ & $\begin{array}{c}0.07 \\
(0.08)\end{array}$ \\
\hline Personal goods $\&$ Services & $\begin{array}{c}0.05 \\
(0.06)\end{array}$ & $\begin{array}{c}0.02 \\
(0.04)\end{array}$ & $\begin{array}{c}0.05 \\
(0.06)\end{array}$ & $\begin{array}{c}0.05 \\
(0.05)\end{array}$ \\
\hline Housing & $\begin{array}{c}0.41 \\
(0.14) \\
\end{array}$ & $\begin{array}{c}0.39 \\
(0.14) \\
\end{array}$ & $\begin{array}{c}0.32 \\
(0.11) \\
\end{array}$ & $\begin{array}{c}0.31 \\
(0.11) \\
\end{array}$ \\
\hline \multicolumn{5}{|l|}{ Budget shares (exclusive goods): } \\
\hline Men's clothing & - & $\begin{array}{c}0.044 \\
(0.057)\end{array}$ & $\begin{array}{c}0.023 \\
(0.026)\end{array}$ & $\begin{array}{c}0.019 \\
(0.023)\end{array}$ \\
\hline Women's clothing & $\begin{array}{c}0.059 \\
(0.059)\end{array}$ & - & $\begin{array}{c}0.029 \\
(0.030)\end{array}$ & $\begin{array}{c}0.022 \\
(0.025)\end{array}$ \\
\hline Child's clothing & - & - & - & $\begin{array}{c}0.022 \\
(0.020)\end{array}$ \\
\hline Total on clothing & $\begin{array}{c}0.059 \\
(0.059) \\
\end{array}$ & $\begin{array}{c}0.044 \\
(0.057) \\
\end{array}$ & $\begin{array}{c}0.052 \\
(0.045) \\
\end{array}$ & $\begin{array}{c}0.063 \\
(0.046) \\
\end{array}$ \\
\hline \multicolumn{5}{|l|}{ Proportion of positive values } \\
\hline $\begin{array}{r}\text { Men's clothing } \\
\text { Women's clothing } \\
\text { Child's clothing }\end{array}$ & $0 . \overline{85}$ & $\begin{array}{c}0.74 \\
-\end{array}$ & $\begin{array}{l}0.74 \\
0.82\end{array}$ & $\begin{array}{l}0.76 \\
0.81 \\
0.90\end{array}$ \\
\hline Sample size & 512 & 497 & 728 & 418 \\
\hline Distribution & 0.24 & 0.23 & 0.34 & 0.19 \\
\hline
\end{tabular}

Figure 1: Descriptive Statistics 


\subsection{An Informal Look at the Data}

The descriptive statistics in Table 1 provide a first overview of the problems we have to address. For one time, let us adopt the traditional Rothbarth way of thinking. If we consider adult goods, we note that the presence of one child reduces the household budget shares devoted to parents' clothing. More importantly, it can be shown that expenditures in absolute terms also decrease. For instance, while the average yearly expenditure on male (female) clothing is €6613 (€766) in childless couples, it drops to $€ 570$ (€647) in couples with one child. The Rothbarth intuition then suggests that, on average, the parents' welfare from consumption (at least) declines when the size of the household increases. This seems to be confirmed by the traditional Engel equivalence scale approach: the budget share devoted to food - a necessary good - increases when the number of persons living in the household increases, which conveys that the household living standard is negatively related to its size.

Yet, the story is not complete. We observe that, in general, the budget share of all the typically private goods (i.e., food, total clothing and, to some extent, personal goods and services) increases with the size of the household while the budget share of typically public goods (i.e., housing) decreases. The simplest interpretation is that economies of scale are substantial, and that these economies of scale are not the same for all goods. ${ }^{9}$ In particular, the decrease in the budget share devoted to housing when the household size increases is consistent with a reduction of the household living standard only if housing is a luxury good, which is certainly not the case. The other explanation is then that the shadow price of housing is much lower in a large household than in a small household. The 'quantity of housing' consumed by household members is larger in larger families but its budget share tends to be lower because of scale economies (and hence lower shadow prices). Economies of scale generate a wealth effect that incites consumption of private goods (provided that the distortion of prices due to economies of scale does not generate

\footnotetext{
${ }^{9}$ The effect of the household size for the other goods, that are partially private and public, is more complicated to interpret and seems to be the result of opposite forces (and, possibly, externalities).
} 
a substitution away from these goods). This mechanism is similar to what is described by Deaton and Paxson (1998).

A first rough estimate of expenditure shares can be obtained from the clothing shares. If the spouses' utility functions were identical and homothetic (so that the budget shares of individual $j$ would be independent of the level of total expenditure she or he made) and if the economies of scale were independent of prices (so that the translation functions $d_{j, n}^{k}(\boldsymbol{z})$ would be equal to zero), then the shares received by each individual would be proportionate to the household budget shares devoted to clothing for each individual,

$$
\eta_{j, 2}(\boldsymbol{z})=\frac{W_{2}^{k}(x, \boldsymbol{z})}{w_{j}^{k}\left(\boldsymbol{z}_{j}\right)},
$$

where good $k$ represent clothing for individual $j$. For instance, the expenditure share of fathers would be equal to $0.30=0.19 / 0.63$, that of mothers to $0.35=0.22 / 0.63$ and that of children to $0.35=0.22 / 0.63$ as well. The latter figure seems to be larger than any realistic measure of the cost of children. Such over-stating, however, may be explained, among other reasons, by economies of scale in the household. Expenditure on children's clothing that are purely private cannot be compressed.

\subsection{Estimations of the Complete Model}

To begin with, we consider four variations of the model. In Model I, all the parameters are free. This model is completely general. To improve the precision of the estimations, we consider three variations which are more restrictive. In Model II, children's parameters $\mathbf{c}_{3}$ and $\mathbf{e}_{3}$ are set to zero. In addition in Model III, scales' parameters $\boldsymbol{\beta}_{1}$ and $\boldsymbol{\beta}_{2}$ are set to zero. In Model IV, the dummies "tertiary education" for both spouses are excluded from the sharing rule. ${ }^{10}$ The most general specification has 238 parameters (out of which

\footnotetext{
${ }^{10}$ The number of optimal solutions of the iterated SURE optimization problem turns out to be large (more than ten for the most general specification). To select the best solution, we used a maximum likelihood criteria. It means that only the estimates for which the average determinant, weighted by the number of observations, of the covariance matrix is the smallest are presented in what follows.
} 
88 are significantly different form zero at the $10 \%$ level) while the most constrained one has 220 parameters (out of which 92 are significantly different from zero). The SmithBlundell residuals prove to be (very) significantly different from zero; therefore, exogeneity of total expenditure is clearly rejected by the data.

The estimated resource shares $\eta_{j, n}(\overline{\mathbf{z}})$ for $j=1,2,3$ evaluated for a representative household, as well as their standard errors, are reported in the upper panel of Table $2 .{ }^{11}$ For childless couples, whatever the specification, the wife's expenditure share is around 0.55 with a standard error of 0.07. By comparison, Browning, Chiappori and Lewbel (2008) report a female share in excess of 0.60 while Lewbel and Pendakur (2008) report a female share between 0.36 and 0.46 with a standard error of 0.08 . One simple interpretation, neglecting the fact that standard deviations are large and resource shares not significantly different from 0.50 , is that women have the leading voice in the household. Note, however, that the household budget shares of goods can be seen as the weighted average of the individual budget shares, with weight being equal to resource shares. In other words, the result in the upper panel of Table 2 simply means that the household budget shares are more similar to women's budget shares than to hudband's. Therefore, we cannot exclude the fact that this similarity stems from self-selection at the time of the marriage or changes in tastes after the marriage.

The share of children - interpreted as the cost of children - is around 0.23 . Other studies based on a more traditional Rothbarth approach obtain estimations of children cost which are much lower. For instance, with United States data, Gronau (1991) estimates the cost of one child at about 0.15 of total expenditure, with Spanish data, Deaton, Ruiz-Castillo and Thomas (1989) at between 0.11 and 0.18 and, with Greek data, Tsakloglou (1991) at between 0.09 and $0.13 .{ }^{12}$ The differences we obtain here compared to more traditional studies is explained by economies of scale. Indeed, in the Rothbarth method, the cost of

\footnotetext{
${ }^{11}$ The representative household is composed of adults aged under 40, no tertiary education, living in a urban area and owning a car. If they have a child, the latter is a boy above 2 .

${ }^{12}$ Deaton and Muellbauer (1986) give measures of the same order using data of developing countries.
} 


\begin{tabular}{|c|c|c|c|c|c|}
\hline Models & & I & II & III & IV \\
\hline \multirow[t]{9}{*}{ Expenditure shares } & Husband's share, no child & $\begin{array}{c}0.440 \\
(0.077)\end{array}$ & $\begin{array}{c}0.436 \\
(0.076)\end{array}$ & $\begin{array}{c}0.445 \\
(0.070)\end{array}$ & $\begin{array}{r}0.453 \\
(0.067)\end{array}$ \\
\hline & Husband's share, one child & $0.335)$ & 0.332 & 0.341 & 0.346 \\
\hline & & $(0.062)$ & $(0.061)$ & $(0.057)$ & $(0.055)$ \\
\hline & Wife's share, no child & 0.560 & 0.564 & 0.555 & 0.547 \\
\hline & & $(0.077)$ & $(0.076)$ & $(0.070)$ & $(0.067)$ \\
\hline & Wife's share, one child & 0.427 & 0.430 & 0.426 & 0.418 \\
\hline & & $(0.061)$ & $(0.060)$ & $(0.056)$ & $(0.054)$ \\
\hline & Child's share & 0.238 & 0.238 & 0.233 & 0.236 \\
\hline & & $(0.035)$ & $(0.035)$ & $(0.038)$ & $(0.038)$ \\
\hline \multirow[t]{16}{*}{$\begin{array}{l}\text { Estimates of husband's } \\
\text { share }\end{array}$} & Constant & -0.165 & -0.171 & -0.163 & -0.133 \\
\hline & & $(0.318)$ & $(0.308)$ & $(0.287)$ & $(0.276)$ \\
\hline & Wife's age (above $40=1$ ) & -0.043 & -0.053 & -0.045 & -0.043 \\
\hline & & $(0.024)$ & $(0.024)$ & $(0.020)$ & $(0.020)$ \\
\hline & Wife's education & 0.012 & 0.017 & 0.010 & - \\
\hline & & $(0.013)$ & $(0.014)$ & $(0.011)$ & \\
\hline & Husband's age (above $40=1$ ) & 0.017 & 0.021 & 0.014 & 0.013 \\
\hline & & $(0.014)$ & $(0.016)$ & $(0.014)$ & $(0.013)$ \\
\hline & Husband's education & 0.001 & 0.004 & -0.001 & - \\
\hline & & $(0.010)$ & $(0.012)$ & $(0.011)$ & \\
\hline & Car Owner & -0.059 & -0.081 & -0.044 & -0.043 \\
\hline & & $(0.041)$ & $(0.048)$ & $(0.028)$ & $(0.027)$ \\
\hline & Urban Resident & 0.037 & -0.045 & -0.016 & 0.014 \\
\hline & & $(0.026)$ & $(0.027)$ & $(0.016)$ & $(0.014)$ \\
\hline & Wage ratio & -0.002 & -0.002 & -0.003 & -0.002 \\
\hline & & $(0.004)$ & $(0.005)$ & $(0.004)$ & $(0.004)$ \\
\hline \multirow[t]{8}{*}{$\begin{array}{l}\text { Estimates of child's } \\
\text { share }\end{array}$} & Constant & -0.578 & -0.579 & -0.601 & -0.570 \\
\hline & & $(0.230)$ & $(0.225)$ & $(0.241)$ & $(0.239)$ \\
\hline & Child's sex $($ female $=1)$ & -0.073 & -0.081 & -0.153 & -0.150 \\
\hline & & $(0.049)$ & $(0.039)$ & $(0.058)$ & $(0.057)$ \\
\hline & Child's age & 0.025 & 0.022 & 0.097 & 0.093 \\
\hline & & $(0.048)$ & $(0.021)$ & $(0.056)$ & $(0.054)$ \\
\hline & Wage ratio & -0.005 & -0.011 & -0.007 & -0.007 \\
\hline & & $(0.009)$ & $(0.006)$ & $(0.009)$ & $(0.009)$ \\
\hline ML criteria & & 45.055 & 45.044 & 45.042 & 45.041 \\
\hline Number of parameters & & 238 & 230 & 222 & 220 \\
\hline
\end{tabular}

Figure 2: Expenditure Shares 
children is obtained as the residual of total expenditure after subtracting the expenditure made for parents. The latter is identified from the comparison of the consumption of adult goods in families with and without children. If the econometrician ignores economies of scale, then she does not take into account their probable wealth effect and will likely infer that adults in the household receive a larger share of total expenditure than what is really the case. $^{13}$

In the lower panel of Table 2, the estimated coefficients of the expenditure shares are reported (the wife's share is the reference and the dummies "tertiary education" are excluded in Model IV because they were not significant). Regarding the distribution of resources between adults, the stable result is that living with older woman reduces men's share. It seems also that men's share is also reduced for couples living in urban area, but this result is not very significant. The distribution factor, i.e., the ratio of wife's earnings to husband's earnings, does not significantly influence the intra-household distribution of resources. ${ }^{14}$ Concerning the expenditure devoted to the child, it appears that boys are favored. Needless to say, however, the larger proportion of total expenditure devoted to boys (by comparison with girls) does not mean that the utility of the former is greater. Without calling upon the impossibility of interpersonal comparisons of utility, boys and girls do not necessarily benefit from the same joint production and are not characterized by the same shadow prices. This result confirms the intuition of Lundberg and Rose (2004), among others, that boy-girl discrimination may be revealed by the structure of consumption. Even without clear-cut conclusions from reduced-form estimations, these

\footnotetext{
${ }^{13}$ In the same vein, estimations conducted under the assumption that there is no economies of scale, that is, $s_{j, n}=d_{j, n}^{k}=0$, give measures of the cost of children that are even lower than those of the authors mentioned above. To make the fact that the budget share devoted to housing expenditure is smaller in large households compatible with a model without economies of scale, the share of expenditure of the parents must be very large, and that of children very small.

${ }^{14}$ Whether she works or not may be the margin that matters in this respect, more than differences in productivities. As explained before, we focus here on two-earner couples and do not have variation in female labor market participation (see Zamora, 2008).
} 
authors show that the gender of children is a significant variable to explain household purchases. ${ }^{15}$

The individual economies of scale $s_{j, n}\left(\overline{\mathbf{z}}_{j}\right)$ for $j=1,2$ are exposed in the upper panel of Table 3. To take an example, if men's deflator is of 0.75 for childless couples (say), the cost of living for a man with a woman is $75 \%$ of the cost he would experience should he live alone. ${ }^{16}$ Moreover, one would expect that scale economies increase (i.e., that deflators decrease) in families compared to childless couples. If these terms are to be interpreted as reflecting scale economies, deflators $s_{j, n}$ should, in principle, lie between 0.50 (complete jointness of consumption) and 1.00 (purely private consumption) for a childless couple and between 0.33 and 1.00 for a couple with child. Taking into account these preliminary considerations, we find that estimates of deflators $s_{j, 2}$ for childless couples are reasonable in magnitude, all located in the $0.5-1.0$ range, but very small. They amount to about 0.50 and 0.60 for men and for women, respectively. These results correspond to slightly smaller deflators, and hence larger scale economies, than those reported in Lewbel and Pendakur (2008). The scales are imprecisely estimated but the results are not very sensitive to the specification. Turning to estimates $s_{j, 3}$ for couples with one child, we find similar results, with scale economies of about 0.40 for men and 0.45 for women. Our results show clearly that, as expected, economies of scale increase with the size of the household.

Overall, economies of scale measured seem to be excessively large. On the basis of the estimates of Model I, the couple's economies of scale, $E_{n}$, amount to 1.73 with a standard deviation of 0.08. By comparison, Browning, Chiappori and Lewbel (2008) obtain economies of scale between 1.27 and 1.41. In all likelihood, our results are to be explained

\footnotetext{
${ }^{15}$ In our estimations, the effects of child's sex on the child's budget shares are not significantly different from zero. Overall, the parameters of the child's budget share (not reported here) are not precisely estimated (except for the effect of child's age).

${ }^{16}$ As explained above, the deflators $s_{j, n}$ could reflect other aspects which are not explicitly accounted for in the model, such as changes in preferences, externalities of consumption, domestic production or changes in the nature (i.e., quality) of purchased goods when married compared to when single.
} 


\begin{tabular}{|c|c|c|c|c|c|}
\hline Models & & I & II & III & IV \\
\hline Economies of scale & $\begin{array}{l}\text { Husband's scale, no } \\
\text { child }\end{array}$ & $\begin{array}{c}0.532 \\
(0.093)\end{array}$ & $\begin{array}{c}0.519 \\
(0.091)\end{array}$ & $\begin{array}{c}0.530 \\
(0.087)\end{array}$ & $\begin{array}{c}0.536 \\
(0.084)\end{array}$ \\
\hline & $\begin{array}{l}\text { Husband's scale, one } \\
\text { child }\end{array}$ & $\begin{array}{c}0.415 \\
(0.076)\end{array}$ & $\begin{array}{c}0.405 \\
(0.074)\end{array}$ & $\begin{array}{c}0.418 \\
(0.072)\end{array}$ & $\begin{array}{c}0.421 \\
(0.070)\end{array}$ \\
\hline & Wife's scale, no child & $\begin{array}{c}0.617 \\
(0.087)\end{array}$ & $\begin{array}{c}0.619 \\
(0.086)\end{array}$ & $\begin{array}{c}0.584 \\
(0.078)\end{array}$ & $\begin{array}{c}0.577 \\
(0.076)\end{array}$ \\
\hline & Wife's scale, one child & $\begin{array}{c}0.485 \\
(0.070)\end{array}$ & $\begin{array}{c}0.487 \\
(0.069)\end{array}$ & $\begin{array}{c}0.463 \\
(0.065)\end{array}$ & $\begin{array}{r}0.455 \\
(0.063)\end{array}$ \\
\hline \multirow[t]{6}{*}{$\begin{array}{l}\text { Estimates of husband's } \\
\text { scale parameters }\end{array}$} & Constant (no child) & $\begin{array}{l}-0.639 \\
(0.173)\end{array}$ & $\begin{array}{l}-0.668 \\
(0.175)\end{array}$ & $\begin{array}{l}-0.648 \\
(0.163)\end{array}$ & $\begin{array}{l}-0.634 \\
(0.156)\end{array}$ \\
\hline & Constant (one child) & $\begin{array}{l}-0.890 \\
(0.181)\end{array}$ & $\begin{array}{l}-0.917 \\
(0.183)\end{array}$ & $\begin{array}{l}-0.887 \\
(0.172)\end{array}$ & $\begin{array}{l}-0.878 \\
(0.166)\end{array}$ \\
\hline & Husband's age & $\begin{array}{l}-0.007 \\
(0.016)\end{array}$ & $\begin{array}{l}-0.005 \\
(0.015)\end{array}$ & - & - \\
\hline & Husband's education & $\begin{array}{l}-0.024 \\
(0.013)\end{array}$ & $\begin{array}{l}-0.004 \\
(0.016)\end{array}$ & - & - \\
\hline & Car & $\begin{array}{c}0.029 \\
(0.029)\end{array}$ & $\begin{array}{l}-0.011 \\
(0.037)\end{array}$ & - & - \\
\hline & Urban & $\begin{array}{c}0.043 \\
(0.022) \\
\end{array}$ & $\begin{array}{c}0.008 \\
(0.024) \\
\end{array}$ & - & - \\
\hline \multirow[t]{6}{*}{$\begin{array}{l}\text { Estimates of wife's scale } \\
\text { parameters }\end{array}$} & Constant (no child) & $\begin{array}{l}-0.564 \\
(0.151)\end{array}$ & $\begin{array}{l}-0.548 \\
(0.147)\end{array}$ & $\begin{array}{l}-0.547 \\
(0.133)\end{array}$ & $\begin{array}{l}-0.558 \\
(0.131)\end{array}$ \\
\hline & Constant (one child) & $\begin{array}{l}-0.805 \\
(0.154)\end{array}$ & $\begin{array}{l}-0.789 \\
(0.151)\end{array}$ & $\begin{array}{l}-0.780 \\
(0.139)\end{array}$ & $\begin{array}{l}-0.796 \\
(0.138)\end{array}$ \\
\hline & Husband's age & $\begin{array}{l}-0.008 \\
(0.016)\end{array}$ & $\begin{array}{l}-0.015 \\
(0.015)\end{array}$ & - & - \\
\hline & Husband's education & $\begin{array}{l}-0.024 \\
(0.013)\end{array}$ & $\begin{array}{l}-0.019 \\
(0.012)\end{array}$ & - & - \\
\hline & Car & $\begin{array}{l}0.029 \\
(0.029)\end{array}$ & $\begin{array}{c}0.027 \\
(0.029)\end{array}$ & - & - \\
\hline & Urban & $\begin{array}{c}0.043 \\
(0.022)\end{array}$ & $\begin{array}{c}0.033 \\
(0.020)\end{array}$ & - & - \\
\hline ML criteria & & 45.055 & 45.044 & 45.042 & 45.041 \\
\hline Number of parameters & & 238 & 230 & 222 & 220 \\
\hline
\end{tabular}

Figure 3: Scale Economies 
by the inclusion of the budget share of housing among the budget shares we model, which is not usual. Note that in a companion paper (Bargain and Donni, 2009), we use a similar desaggregation and obtain a confirmation of the present measure of scale economies when using data for another country (Ireland). ${ }^{17}$

The indifference scales, interpreted as the scale to household income that puts a single individual on the same indifference curve as if living in couple, can easily be computed by dividing scale economy deflator by the expenditure share. At the sample mean, using the estimates of Model I, the indifference scales, $I_{1,2}$ and $I_{2,2}$, of a woman and a man in a childless couple are 1.10 and 1.21 with a standard deviation of 0.03 and 0.10 , respectively This implies that such a woman (man), if living alone, would need $0.90 \approx 1 / 1.10(0.83 \approx$ $1 / 1.21$ ) of the couple's income to reach the same indifference curve as when in couple. This is clearly larger than a half because the single woman (man) would not benefit from scale economies. In comparison, the indifference scales in a couple with a child, $I_{1,3}$ and $I_{2,3}$, would be equal to 1.14 and 1.24 with a standard deviation of 0.03 and 0.10 , respectively. Interestingly, the indifference scales are estimated quite precisely in spite of the relatively large standard deviations of scale economies and expenditure shares.

\section{Conclusion}

In this paper, we have suggested a new method to estimate the cost of children that generalizes the more conventional Rothbarth method. This approach is consistent with the existence of economies of scale and parental bargaining. Our empirical results on French data indicate that child costs are much lower than what is obtained in traditional studies. Deaton and Muellbauer (1986) point out that the measures from the Rothbarth method

\footnotetext{
${ }^{17}$ Nelson (1989) estimates the economies of scale associated to each good (including housing). She obtains estimations that are very large and probably larger than ours. In particular, economies of scale for housing seems superior to what would be in the case of pure joint consumption. She explains it by increasing returns in household production
} 
are likely downward biased, but they did not propose an alternative strategy. Our method provides estimations of the cost of children that amount to $23-24 \%$ of total expenditure, which seems more realistic The other important empirical contributions of this paper are two-fold. Firstly, we show that, as far as expenditure on housing are considered, economies of scale in the household may be very large. Secondly, the expenditure made by parents for boys seems to be larger than for girls.

One final remark is in order. Even if, in our opinion, the estimations obtained here are more realistic than what is generally reported, there are reasons to believe that these estimations still understate the true values of the cost of children. Indeed, the time devoted by parents to child care, which certainly represents a significant fraction of nonmarket time, is not incorporated in our model. In particular, the mothers' part-time participation in the labor market that we observe in the data may well be associated with the provision of child care. To account for child care, future work should certainly incorporate labor supply decisions.

\section{References}

[1] Banks, Jeffrey, Richard W. Blundell, Arthur Lewbel (1997), "Quadratic Engel Curves and Consumer Demand", Review of Economics and Statistics, vol. 79, No. 4, pp. $527-539$.

[2] Bargain, Olivier and Olivier Donni (2008), "Indirect Taxation, Targeting and Child Poverty", Working Paper, University College of Dublin.

[3] Bargain, Olivier, Olivier Donni and Monnet Gbakou (2009), "The Measurement of Child Costs: Evidence from Ireland", Working Paper, University College of Dublin.

[4] Blackorby, Charles and D. Donaldson. (1990), "Adult Equivalence Scalesand the Economic Implementation of Interpersonal Comparisons of Well-being", Econo- 
metrica,

[5] Blundell, Richard W. and Arthur Lewbel (1991), "The Information Content of Equivalence Scales", Journal of Econometrics, vol. 50, pp. 49-68.

[6] Blundell, Richard W. and Jean-Marc Robin (1999), "Estimation in Large and Disaggregated Demand Systems: An Estimator for Conditionally Linear Systems", Journal of Applied Econometrics, vol. 14, pp. 209-232

[7] Blundell, Richard and Jean-Marc Robin (2000), "Latent Separability: Grouping Goods Without Weak Separability", Econometrica, vol. 68, No. 1, pp. 53-84.

[8] Blundell, Richard, Pierre-André Chiappori and Costas Meghir (2005), "Collective labor supply with children", Journal of Political Economy, vol. 113, No. 6, pp. $1277-1306$

[9] Bourguignon, François (1999), "The cost of children: May the collective approach to household behaviour help?" Journal of Population Economics, vol. 12, No. 4, pp. $503-522$.

[10] Bourguignon, François, Martin Browning and Pierre-André (2008), "Efficient IntraHousehold Allocations and Distribution Factors: Implications and Identification", Review of Economics Studies, vol. 76, pp. 503-528.

[11] Browning, Martin (1992), "Children and Household Economic Behavior", Journal of Economic Literature, vol. 30, pp. 1434-1475.

[12] Browning, Martin and Pierre-André Chiappori (1998), "Efficient Intrahousehold Allocations: A General Characterization and Empirical Tests", Econometrica, vol. 56, pp. $1241-1278$.

[13] Browning, Martin, Pierre-André Chiappori and Arthur Lewbel (2008), "Estimating Consumption Economies of Scale, Adult Equivalence Scales, and Household Bargaining Power", Working Paper, Boston College. 
[14] Chiappori, Pierre-André and Olivier Donni (2010), "Non-Unitary Models of Household Behavior: A Survey of the Literature". In: A. Molina (eds), Household Economic Behaviors, Berlin: Springer.

[15] Deaton, Angus, Javier Ruiz-Castillo, Duncan Thomas (1989), "The Influence of Household Composition on Household Expenditure Patterns: Theory and Spanish Evidence", Journal of Political Economy, vol. 97, pp.179-200.

[16] Deaton, Angus and Christina Paxson (1998), "Economies of Scale, Household Size, and the Demand for Food", Journal of Political Economy, vol. 106, pp. 97-930.

[17] Deaton, Angus and John Muellbauer (1986), "On Measuring Child Costs: With Applications to Poor Countries", Journal of Political Economy, vol. 94, No. 4, pp. $720-744$.

[18] Donni, Olivier (2009), "A Simple Approach to Investigate Intrahousehold Allocation of Private and Public Goods", The Review of Economics and Statistics, vol. 91, No. 3, pp. 617-628.

[19] Gronau, Reuben (1988), "Consumption Technology and the Intrafamily Distribution of Resources: Adult Equivalence Scales Reexamined", Journal of Political Economy, vol. 96, No. 6, pp. 1183-1205.

[20] Gronau, Reuben (1991), "The Intrafamily Allocation of Goods - How to Separate the Adult from the Child", Journal of Labor Economics, vol. 9, No. 3, pp. 207-235.

[21] Lazear, Edward P. and R.T. Michael (1988), Allocation of Income within the Household, Chicago: University of Chicago Press.

[22] Lewbel, Arthur (1989), "Household Equivalence Scales and Welfare Comparisons", Journal of Public Economics, vol. 39, pp. 377-391.

[23] Lewbel, Arthur (1991), "Cost of Characteristics Indices and Household Equivalence Scales", European Economic Review, vol. 35, pp.1277-1293.

[24] Lewbel, Arthur (1997), "Consumer Demand Systems and Household Equivalence 
Scales". In: M.H. Pesaran and P. Schmidt (ed), Handbook of Applied Econometrics, Volume II: Microeconomics, Oxford: Blackwell Publishers Ltd.

[25] Lewbel, Arthur, (2003), "Calculating Compensation in Cases of Wrongful Death," Journal of Econometrics, vol. 113, pp. 115-128.

[26] Lewbel, Arthur and Krishna Pendakur (2008), "Estimation of Collective Household Models with Engel Curves", Journal of Econometrics, vol. 148, pp. 350-358.

[27] Lunberg, Shelly and Elaina Rose (2004), "Investments in Sons and Daughters: Evidence from the Consumer Expenditure Survey" in: Ariel Kalil and Thomas DeLeire (eds), Family Investments in Children's Potential: Resources and Parenting Behaviors That Promote Success, Mahwah, N.J.: Lawrence Erlbaum Associates Inc.

[28] Matzkin, Rosa L. (2008), "Nonparametric Identification", in: J. Heckman and E. Leamer (eds), Handbook of Econometrics, vol. VI, pp. Elsevier.

[29] Nelson, Julie A. (1988), "Household Economies of Scale in Consumption: Theory and Evidence", Econometrica, vol. 56, pp. 1301-1314.

[30] Pendakur, Krishna (1999), "Estimates and Tests of Base-Independent Equivalence Scales", Journal of Econometrics, vol. 88, pp. 1-40

[31] Pollak Robert and Terence J. Wales (1979), "Welfare Comparisons and Equivalence Scales", American Economic Review, vol. 69, pp. 216-221.

[32] Pollak, Robert and Terence J. Wales (1992), Demand System Specification and Estimation, New York: Oxford University Press.

[33] Smith, Richard J. and Richard W. Blundell (1986), "An Exogeneity Test for a Simultaneous Equation Tobit Model with an Application to Labor Supply", Econometrica, vol. 54, No. 3, pp. 679-685.

[34] Tsakloglou, Panos (1991), "Estimation and Comparison of Two Simple Models of Equivalence Scales for the Cost of Children", The Economic Journal, vol. 101, 
No. 405, pp. 343-357.

[35] Zamora, B. (2008): "Does female participation affect the sharing rule?", Journal of Population Economics 